\title{
Zoneamento agroclimático da cultura da videira no Estado do Paraná
}

\section{Agroclimatic zoning for grapevine cultivation in the state of Paraná, Brazil}

\author{
Wilian da Silva Ricce ${ }^{1 *}$; Sérgio Luiz Colucci de Carvalho²; \\ Paulo Henrique Caramori'; Sergio Ruffo Roberto ${ }^{4}$
}

Resumo

O estado do Paraná localiza-se em uma região de transição climática, com regimes térmicos diferentes e variações no risco de geadas. O conhecimento dos riscos climáticos a que a cultura da videira (Vitis $s p$.) estará exposta é importante para o sucesso de seu cultivo. O objetivo deste trabalho foi efetuar o zoneamento agroclimático para a cultura da videira no estado do Paraná. Para tanto, foram utilizados dados de 21 estações meteorológicas convencionais do IAPAR, nas diversas regiões do estado, com períodos de observação de 1976 a 2010. Foram considerados três grupos de uvas: rústicas, finas de mesa e finas para vinificação. Para cada grupo foram avaliados a deficiência hídrica anual, o risco de geadas tardias, a temperatura média anual, o volume de precipitação anual e a umidade relativa média anual. O principal risco climático é a umidade relativa alta que, combinada com a temperatura alta do ar, pode favorecer a ocorrência de doenças fúngicas e comprometer o potencial produtivo da cultura. Para as uvas rústicas, somente o litoral do estado do Paraná não foi considerado apto ao cultivo. Para o cultivo de uvas finas de mesa, somente as regiões norte, noroeste e oeste são consideradas aptas, e para as uvas finas destinadas à vinificação, somente o litoral e a região leste não são considerados aptos, segundo os critérios estabelecidos.

Palavras-chave: Riscos climáticos, Vitis $s p$., viticultura, aptidão climática

\begin{abstract}
The state of Paraná is located in a climate transition region, with different thermal regimes and variations in the risk of frost. Knowledge of the climate risks to which grapevine (Vitis sp.) will be exposed is important to the success of the vineyard. The objective of this study was to perform the agroclimatic zoning for the growing vines in the state of Paraná. Historical data from 21 conventional weather stations of Instituto Agronômico do Paraná were used in different regions of the state with observation periods from 1976 to 2010. Three groups of grapes were considered: rustic grapes, fine table grapes and fine grapes for winemaking. For each group it was evaluated: the annual water deficit, the risk of late frosts, the average annual temperature, the volume of annual precipitation and relative humidity. The main climate risk is the high relative humidity which, combined with high temperature, may favor the occurrence of fungal diseases and compromise the vineyard. For rustic grapes, only the coast of the state of Paraná was not suitable for cultivation. For the cultivation of fine table grapes, only the northern,
\end{abstract}

\footnotetext{
${ }^{1}$ Pesquisador da Empresa de Pesquisa Agropecuária e Extensão Rural de Santa Catarina, EPAGRI, CIRAM, Florianópolis, SC. E-mail: wilianricce@epagri.sc.gov.br

${ }^{2}$ Pesquisador do Instituto Agronômico do Paraná, Fitotecnia, IAPAR, Londrina, PR. E-mail: slccarva@iapar.br

${ }^{3}$ Pesquisador do IAPAR, Agrometeorologia, Londrina, PR. E-mail: caramori@iapar.br

${ }^{4}$ Prof. do Dept ${ }^{\circ}$ de Agronomia/Fitotecnia, Universidade Estadual de Londrina, UEL, Londrina, PR. E-mail: sroberto@uel.br

* Autor para correspondência
} 
northwestern and western regions are apt, and for fine grapes for winemaking, only the coast and east are not considered suitable, according to established criteria.

Key words: Climatic risks, Vitis sp., viticulture, climatic aptitude

\section{Introdução}

No Brasil, a área total da cultura da videira no ano de 2011 ocupou 84.339 ha, com produção de $1.542 .068 \mathrm{t}$ e rendimento médio de $18.284 \mathrm{~kg} / \mathrm{ha}$ (IBGE, 2010). A viticultura brasileira concentra-se nas regiões sul, sudeste e nordeste, sendo os estados do Rio Grande do Sul, São Paulo, Pernambuco, Paraná, Santa Catarina, Bahia, e Minas Gerais, os principais produtores em ordem decrescente. No Paraná, a área total da cultura da videira, no ano de 2011, ocupou 6.064 ha, com produção de 83.948 t e rendimento médio de $13.844 \mathrm{~kg} / \mathrm{ha}$ (IPARDES, 2013).

Para o planejamento adequado da atividade agrícola, é importante conhecer os riscos climáticos da região em que se pretende implantar a cultura. Os elementos meteorológicos que mais influenciam o crescimento e o desenvolvimento da videira são: radiação solar, temperatura do ar, precipitação pluviométrica, umidade relativa do ar e vento (KISHINO; CARAMORI, 2007).

A temperatura do ar apresenta diferentes efeitos sobre a videira, variáveis em função das diferentes fases do ciclo vegetativo ou de repouso da planta, sendo que no inverno a videira pode suportar temperaturas mínimas de até $-20^{\circ} \mathrm{C}$ no caso da espécie Vitis vinifera. O frio invernal é importante para a quebra de dormência das gemas, no sentido de assegurar uma brotação adequada para a videira. $\mathrm{Na}$ primavera, de forma genérica, considera-se a temperatura de $10^{\circ} \mathrm{C}$ como mínima para que possa haver desenvolvimento vegetativo. Geadas tardias podem prejudicar as brotações novas das videiras. No período de floração, temperaturas iguais ou superiores a $18^{\circ} \mathrm{C}$ são favoráveis, sobretudo se associadas a dias de elevada insolação e baixa umidade do ar. No verão, a maior atividade fotossintética ocorre na faixa de temperaturas entre
20 e $25^{\circ} \mathrm{C}$, sendo que temperaturas a partir de $35^{\circ} \mathrm{C}$ são prejudiciais. No outono, a temperatura afeta o comprimento do ciclo vegetativo da videira, que é importante para a maturação dos ramos e o acúmulo de reservas pela planta (EMBRAPA UVA E VINHO, 2003).

Quanto à precipitação pluviométrica, Soares e Costa (2009) discutem que o consumo de água da videira fica em torno de 450 a $900 \mathrm{~mm}$. Pommer (2003) destaca que a videira é considerada resistente à seca por seu sistema radicular ser capaz de atingir grandes profundidades. $\mathrm{O}$ excesso de chuvas pode ser prejudicial à qualidade dos frutos e contribuir para a ocorrência de doenças, principalmente, se estiver combinado com alta umidade relativa, temperatura elevada e molhamento foliar. O míldio é a principal doença da videira no Brasil, atacando todas as partes verdes da videira. Os danos são maiores quando ataca os cachos, podendo causar perda total da produção se medidas adequadas de controle não forem tomadas no momento adequado (TESSMANN et al., 2007).

O zoneamento agroclimático da cultura da videira para o estado do Paraná é importante para subsidiar as políticas agrícolas, conjugando o potencial de expansão da cultura com a abertura de linhas de crédito voltadas ao desenvolvimento econômico da vitivinicultura. É também, ferramenta importante para tomada de decisão de técnicos e produtores para a implantação de novos parreirais.

Tendo em vista a diversidade de condições climáticas presentes no estado do Paraná, a cultura da videira é exposta a diferentes graus de riscos climáticos, conforme a região de cultivo. Assim, o objetivo deste trabalho foi efetuar o zoneamento agroclimático para a cultura da videira no estado do Paraná. 


\section{Material e Métodos}

Para análise dos riscos climáticos para a cultura da videira no estado do Paraná foram utilizados dados de 21 estações meteorológicas convencionais do IAPAR distribuídas pelo estado com períodos de observação de 1976 a 2010. Em complementação a esses dados, foram utilizadas séries históricas de precipitação do Instituto das Águas do Paraná, no mesmo período, totalizando 476 pontos de registro (Figura 1).

Figura 1. Distribuição das estações meteorológicas e pluviométricas no estado do Paraná.

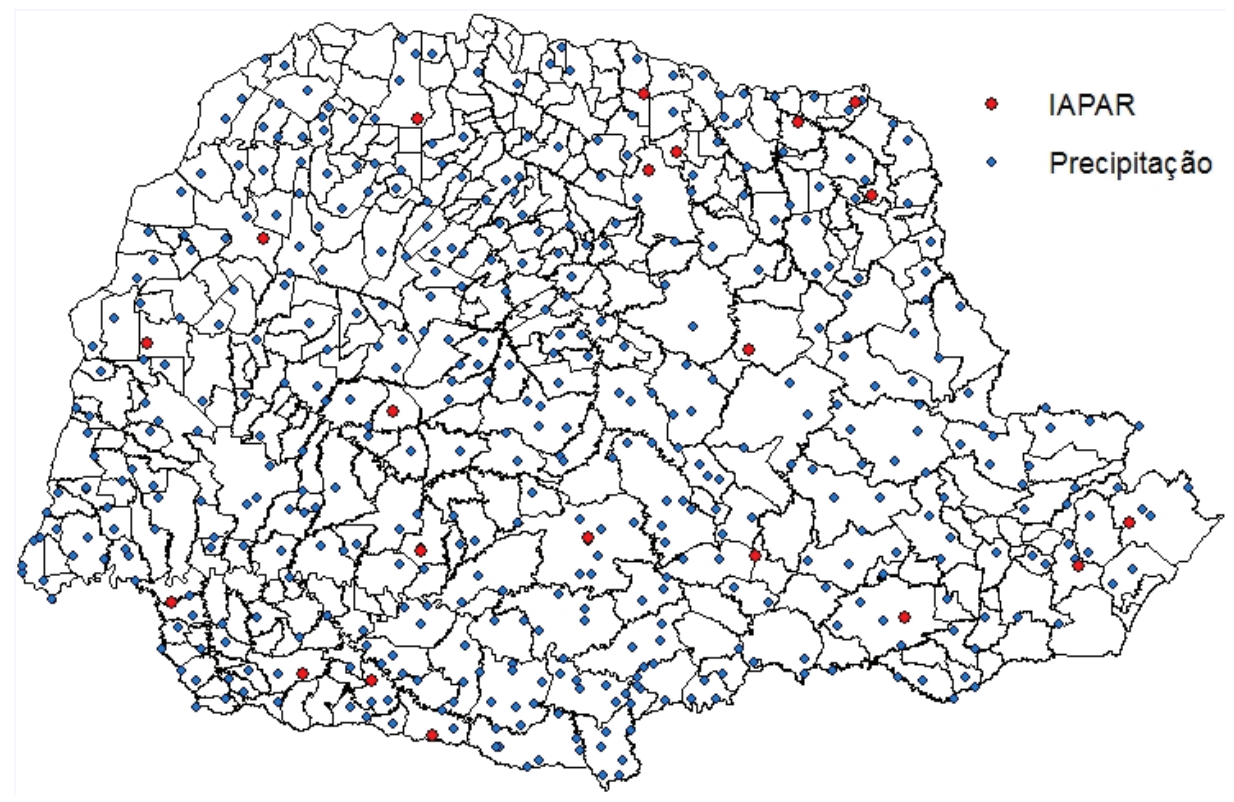

Fonte: Elaboração dos autores.

As variedades de uvas foram divididas em três categorias, com os seguintes parâmetros de riscos:

a) Uvas rústicas (Vitis labrusca e seus híbridos), destinadas ao consumo de frutas frescas e ao processamento ('Isabel' e 'Niágara'). Áreas com umidade relativa média anual superior a $85 \%$, precipitação superior a $2.000 \mathrm{~mm}$ e temperatura média anual superior a $20^{\circ} \mathrm{C}$ foram consideradas inaptas por apresentarem elevado risco de doenças;

b) Uvas finas de mesa (Vitis vinifera) ou para consumo de frutas frescas ('Itália', 'Rubi', 'Benitaka' e 'Brasil'). Áreas com precipitação média anual superior a $1.800 \mathrm{~mm}$, umidade relativa média anual superior a $75 \%$ e temperatura média anual superior a $20^{\circ} \mathrm{C}$ foram consideradas inaptas por apresentarem elevado risco de doenças; c) Uvas finas para vinificação (Vitis vinifera) ('Cabernet Sauvignon', 'Merlot' e 'Syrah'). Áreas com umidade relativa média anual superior a $85 \%$ ou precipitação superior a $1.800 \mathrm{~mm}$ e temperatura média anual superior a $20^{\circ} \mathrm{C}$ foram consideradas inaptas por apresentarem elevado risco de doenças.

A deficiência hídrica anual (Dha) (THORNTHWAITE; MATHER, 1955) foi obtida pelo cálculo do balanço hídrico climatológico normal. Para a capacidade de água disponível (CAD) no solo, utilizou-se o valor de $100 \mathrm{~mm}$, com o auxílio da planilha desenvolvida por Rolim, Sentelhas e Barbieri (1998). Os resultados obtidos foram interpolados em um sistema de informação geográfica para a geração dos mapas de deficiência hídrica anual. Para o risco de deficiência hídrica foi 
considerado: Alto Risco: Dha $>100 \mathrm{~mm}$ e Baixo Risco: Dha $<100 \mathrm{~mm}$.

Foram utilizadas as séries históricas de temperatura mínima inferiores a $1^{\circ} \mathrm{C}$, observadas no interior dos abrigos meteorológicos para calcular os riscos de geadas tardias (CARAMORI et al., 2008). Foram calculadas as probabilidades de ocorrência em setembro utilizando a distribuição de valores extremos pelo método dos momentos seguindo procedimento descrito por Assis, Arruda e Pereira (1996). Obteve-se uma equação de regressão entre as probabilidades de geada com base na latitude, longitude e altitude de cada estação: risco de geada de setembro $=100 *(-0,51646-0,01578 *$ [latitude] - $0,00088 *$ [longitude] $+0,00018 *$ [altitude]). Riscos maiores que $25 \%$ foram considerados limitantes para a cultura. Para a temperatura média anual também foi gerada a equação de regressão: temperatura média anual $=21,33504+0,78655$ * [latitude] - 0,41483* [longitude] - 0,00534* [altitude]. Utilizando as regressões ajustadas, foram mapeados os riscos de geadas e a temperatura média anual em para todo o estado do Paraná, com resolução espacial de $90 \mathrm{~m}$, utilizando a base do SRTM Shuttle Radar Topography Mission (MIRANDA, 2005). Para precipitação e umidade relativa, foram gerados mapas através da interpolação por krigagem em ambiente SIG.

\section{Resultados e Discussão}

Observa-se na Figura 2 que o litoral é a região com maior pluviosidade no estado devido ao efeito de oceanidade e orografia. Já o sudoeste apresenta precipitações anuais que ultrapassam $2.000 \mathrm{~mm}$, essa região é a entrada das frentes frias no estado. A característica da transição climática do estado do Paraná, regiões de clima subtropical ao sul e tropical ao norte e noroeste, faz com que exista maior diferenciação entre a estação seca e chuvosa nas regiões norte e oeste, enquanto no sul as chuvas são mais uniformemente distribuídas durante o ano (PEREIRA et al., 2008). Sampaio et al. (2007) descrevem que o estado do Paraná apresenta decréscimo da precipitação na direção litoral/oeste e sul/norte.

Figura 2. Precipitação normal anual (mm) no estado do Paraná (1976-2010).

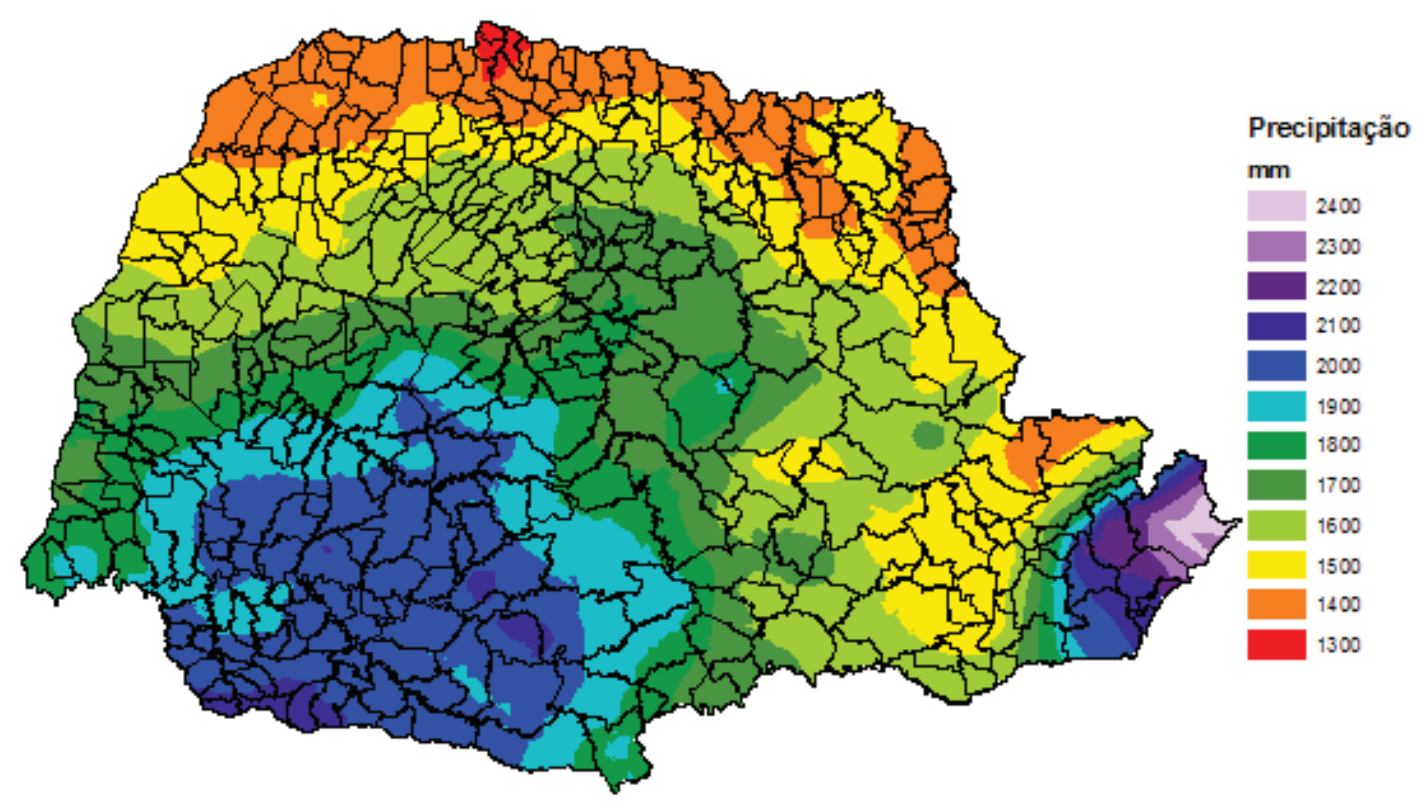

Fonte: Elaboração dos autores. 
A deficiência hídrica anual não foi limitante para a cultura da videira no estado do Paraná. Apenas em alguns anos, como 1985 e 1988, quando ocorreram baixas precipitações, a deficiência hídrica anual superou os $100 \mathrm{~mm}$. Porém, com base nos dados normais climatológicas, as estações meteorológicas apresentam valores de deficiência hídrica inferiores a $50 \mathrm{~mm}$ nas regiões norte e noroeste do estado, e ausência de deficiência para as outras regiões.

Nas regiões norte e noroeste do estado, onde as temperaturas são mais elevadas e o volume de precipitação é menor em relação ao sul, podese optar por porta-enxertos que tenham bom desenvolvimento radicular e maior capacidade de exploração do solo, como exemplo, os portaenxertos IAC 766 e IAC 572 que apresentam tais características (KISHINO; CARVALHO; ROBERTO, 2007).

No estado do Paraná, a média histórica de precipitação mínima é em torno de $1.300 \mathrm{~mm}$. A ocorrência de excesso de chuva pode ser prejudicial à cultura da videira pela maior favorabilidade à ocorrência de doenças. Na Serra Gaúcha também ocorre uma tendência histórica ao excesso de chuvas no período de maturação, o que pode prejudicar a qualidade da uva em função da ocorrência de podridões ou pela necessidade de colheitas antecipadas (TONIETTO; FALCADE, 2003).

Verificam-se na Figura 3, que na região litorânea a umidade do ar é muito elevada, com valores médios superiores a $90 \%$. Na região metropolitana de Curitiba são encontrados valores de umidade relativa entre 80 e $85 \%$, diminuindo nos Campos Gerais e nas regiões sudoeste e oeste, com os menores valores registrados nas regiões norte e noroeste do estado. Excesso de umidade relativa pode favorecer a ocorrência de doenças na cultura da videira, sendo que quando acima de $75 \%$ associada à temperatura alta durante o período vegetativo, favorece a infecção por míldio, podridão do fruto, mancha-da-folha e ferrugem, pois prolonga o período de molhamento foliar sobre os tecidos da planta em uvas finas para mesa (KISHINO; CARAMORI, 2007).

Verificam-se na Figura 4, que os valores de temperatura média normal anual evidenciam o papel importante do relevo no regime térmico, associado às variações de latitude. Observam-se diferenças de $12 \mathrm{a} 13^{\circ} \mathrm{C}$ na temperatura média normal anual entre o extremo noroeste do estado, junto ao vale do Rio Paraná onde a média anual pode atingir 24 a $25^{\circ} \mathrm{C}$ e as áreas mais elevadas do sul (acima de $1.200 \mathrm{~m}$ ) onde a média anual é de 13 a $14^{\circ} \mathrm{C}$.

O risco de geadas tardias é inferior ao limite estipulado em todo o estado do Paraná, o que permite o desenvolvimento e produção da cultura da videira nas regiões mais frias do estado, recomendando-se a adoção de medidas protecionistas em noites com risco de geada para diminuir as perdas (KISHINO; CARAMORI, 2007; CARAMORI; ANDROCIOLI FILHO; MORAIS, 2007), principalmente quando antecipa-se a poda para a produção em época de menor oferta. Porém, para as uvas de mesa, podas tardias favorecem colheitas em épocas de pico de produção em outras regiões produtoras do país, o que pode resultar em menores preços e queda na rentabilidade do produtor.

A região norte do estado do Paraná não apresenta restrições térmicas para o cultivo das variedades destinadas à produção de uvas finas de mesa, e a principal limitação é a ocorrência de precipitações intensas ao longo do ano, o que propicia condições favoráveis para o desenvolvimento de doenças fúngicas, como o míldio (EMBRAPA UVA E VINHO, 2005). O fungo requer umidade elevada, entre 95 e $100 \%$, e pelo menos 4 horas de escuridão e a temperatura ótima é de 18 a $22^{\circ} \mathrm{C}$, para a formação dos esporângios no tecido colonizado, enquanto temperaturas diurnas acima de $30^{\circ} \mathrm{C}$ reduzem sua viabilidade (TESSMANN et al., 2007). 
Figura 3. Umidade relativa do ar média normal anual (\%) no estado do Paraná (1976-2010).

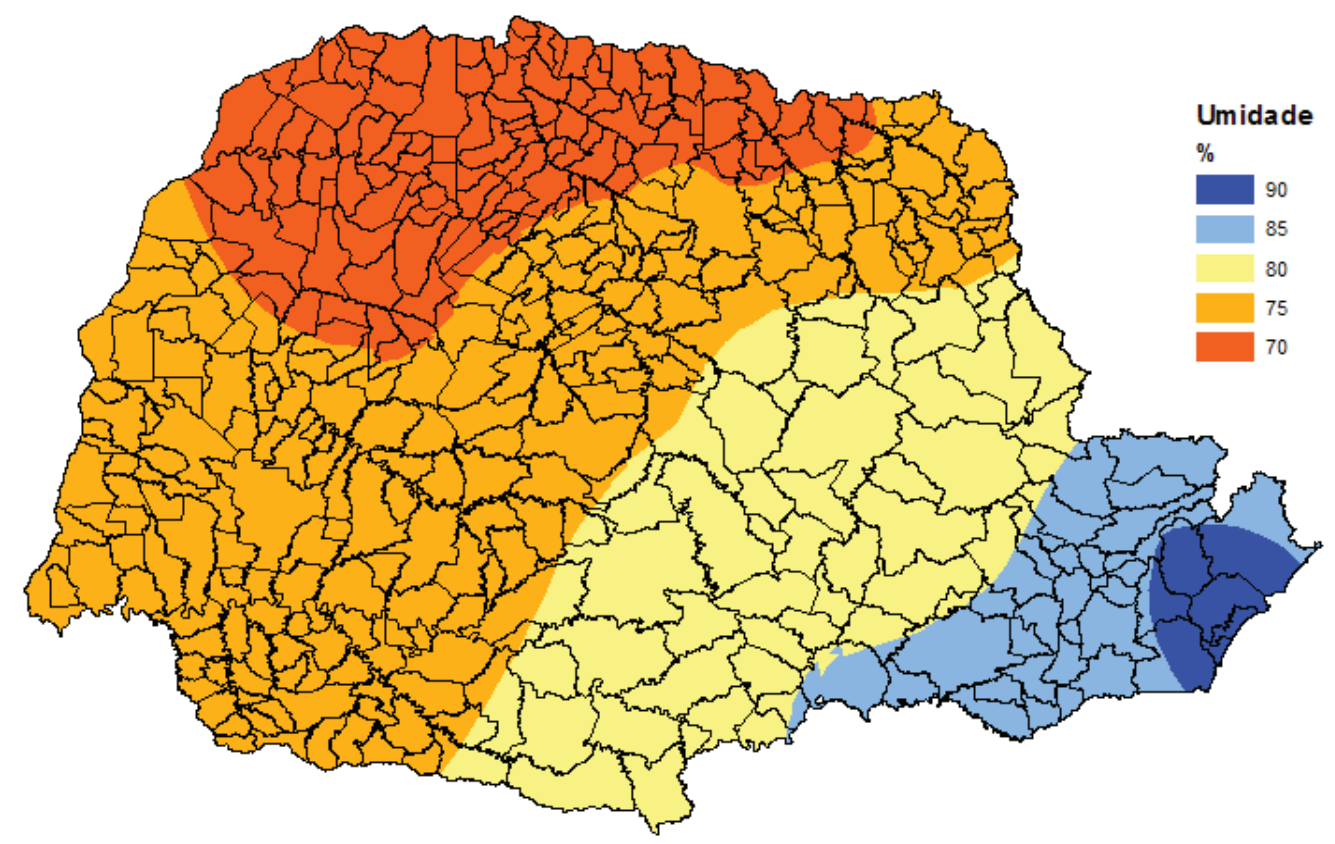

Fonte: Elaboração dos autores.

Figura 4. Temperatura média normal anual $\left({ }^{\circ} \mathrm{C}\right)$ no estado do Paraná (1976-2010).

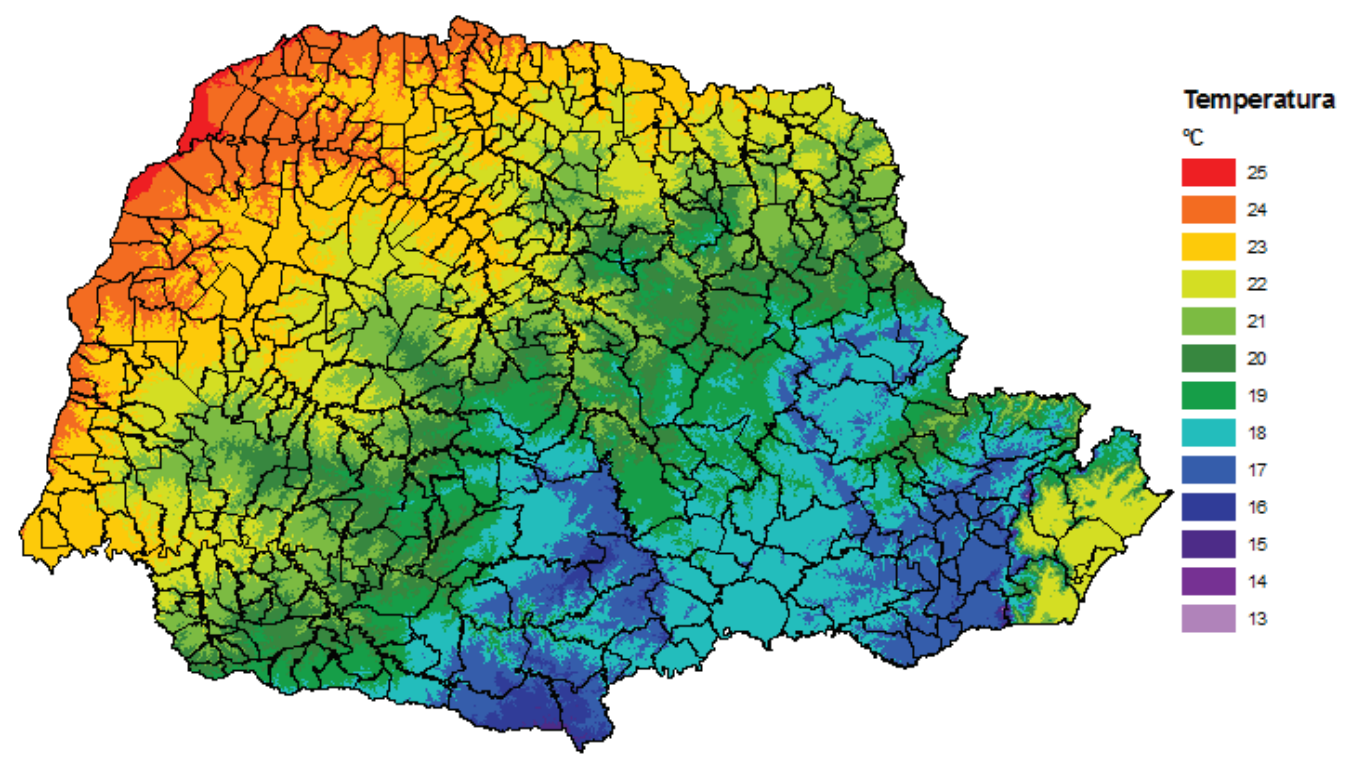

Fonte: Elaboração dos autores.

Para as uvas rústicas, somente o litoral do estado do Paraná foi considerado inapto, pois essa região apresenta condição extremamente favorável ao desenvolvimento de doenças fúngicas, devido a elevada umidade do ar e temperatura, o que poderia não ser economicamente viável (Figura 5).

As uvas européias são mais suscetíveis ao míldio que as americanas e híbridas, por isso as regiões com alta umidade do ar não são recomendadas. Dessa forma, o cultivo de uvas finas de mesa 
foi considerado apto somente nas regiões norte, noroeste e oeste do estado com base nos critérios estabelecidos. Para as uvas finas de mesa, os critérios foram mais rigorosos, pois essas dependem da apresentação final para serem consumidas in natura. A combinação de alta umidade do ar, precipitações abundantes e altas temperaturas é extremamente favorável ao desenvolvimento de doenças fúngicas, o que prejudica diretamente a produtividade e qualidade dessas uvas.

Figura 5. Zoneamento agroclimático da cultura da videira no Paraná (A): uvas rústicas, (B): uvas finas para vinho e (C): uvas finas de mesa, sendo a área violeta apta e a área em branco inapta ao cultivo.

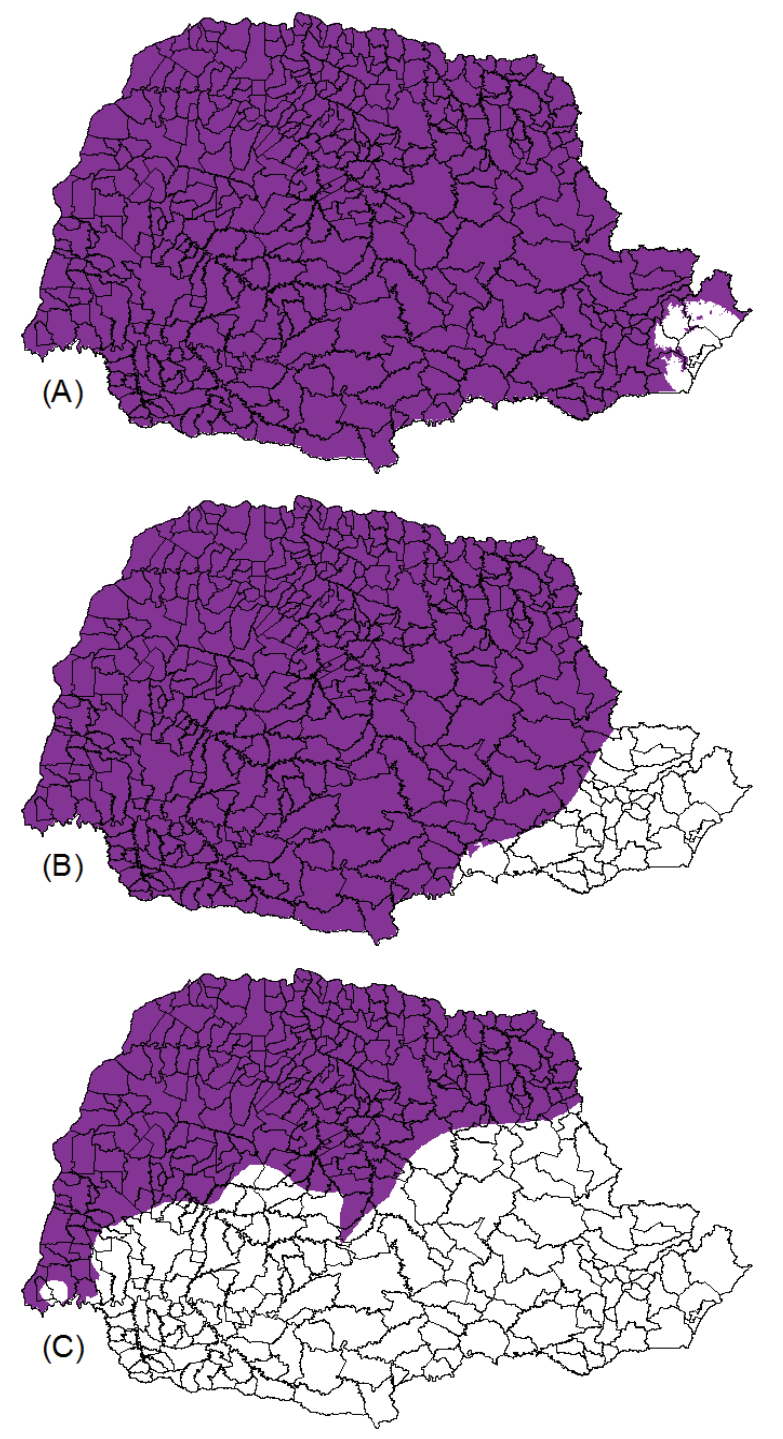

Fonte: Elaboração dos autores.
Para as uvas finas para vinificação, as regiões leste e o litoral do estado foram consideradas inaptas pelo excesso de umidade do ar, sendo o restante do estado apto ao cultivo. Segundo IBRAVIN (2013), a umidade relativa do ar média anual situa-se entre 71 e $76 \%$ na Campanha e Serra do Sudeste, e 76\% na Serra Gaúcha, regiões de destaque na produção de vinhos finos no Rio Grande do Sul.

Para a realização do zoneamento agroclimático, o conhecimento regional é extremamente importante para as recomendações. Por isso, existem diferenças regionais para os parâmetros considerados como de risco para a mesma cultura. Para o zoneamento agroclimático da videira européia no estado de Pernambuco, Teixeira e Azevedo (1996) utilizaram como parâmetros a temperatura média e o índice hídrico anual de Thornthwaite.

Teixeira et al. (2002), avaliando a aptidão agroclimática da cultura da videira no estado da Bahia, confeccionaram cartas das isotermas dos meses mais quentes e mais frios do ano, e do índice hídrico anual, considerados parâmetros mais importantes na determinação do grau de aptidão agroclimática da cultura.

Para o estado de Santa Catarina, a EPAGRI (2013) utilizou como parâmetros para o zoneamento agroclimático, o número de horas de frio, a ocorrência de geadas no mês de setembro, a altitude e o volume de precipitação na época de maturação dos frutos. Os autores recomendaram praticamente todo o estado para as uvas americanas, com exceção do litoral norte. Para as uvas finas, somente as regiões mais frias na parte central do estado foram recomendadas.

Para realizar o zoneamento de $V$. vinifera no Rio Grandedo Sul, Westphalene Maluf(2000), utilizaram o número de horas de frio, risco de geadas, excesso hídrico e vários índices bioclimáticos baseados em temperatura, precipitação, evapotranspiração, fotoperíodo e insolação para a caracterização das áreas bioclimáticas. Assim, foram indicadas para o cultivo de videira européia as regiões da Serra 
do Nordeste - Planalto e da Serra do Sudeste Campanha.

Além dos aspectos técnicos aqui considerados, o zoneamento agroclimático para a cultura da videira gerado nesse trabalho torna-se um instrumento de política agrícola e gestão de riscos para a agricultura do estado do Paraná, uma vez que alguns agentes financeiros condicionam a concessão do crédito rural ao uso do zoneamento (MAPA, 2013).

\section{Conclusões}

O estado do Paraná possui regiões com baixo risco climático para a cultura da videira. Para as uvas rústicas, praticamente todo o estado é apto ao cultivo, com exceção do litoral. Para o cultivo de uvas finas de mesa, somente as regiões norte, noroeste e oeste são consideradas aptas. Para as uvas finas destinadas à vinificação, somente o litoral e a região leste não são aptas, segundo os critérios estabelecidos.

\section{Agradecimentos}

Agradecimento a CAPES pela bolsa de doutorado ao autor principal e ao CNPq pelo financiamento da pesquisa através do Edital Universal.

\section{Referências}

ASSIS, F. N.; ARRUDA, H. V.; PEREIRA, A. R. Aplicações de estatística à climatologia - teoria e prática. Pelotas: Universidade Federal de Pelotas, 1996. 161 p.

CARAMORI, P. H.; ANDROCIOLI FILHO, A.; MORAIS, H. Sistema de alerta para geadas na cafeicultura do Paraná. Informe Agropecuário, Belo Horizonte, v. 28, n. 241, p. 66-71, nov./dez. 2007.

CARAMORI, P. H.; CAVIGLIONE, J. H.; WREGE, M. S.; HERTER, F. G.; HAUAGGE, R.; GONÇALVES, S. L.; CITADIN, E.; RICCE, W. S. Zoneamento agroclimático para o pessegueiro e a nectarineira no estado do Paraná. Revista Brasileira de Fruticultura, Cruz das Almas, v. 30, n. 4, p. 1040-1044, 2008.

EMPRESA BRASILEIRA DE PESQUISA AGROPECUÁRIA - EMBRAPA UVA E VINHO.
Sistema de produção de uva de mesa no norte do Paraná. embrapa uva e vinho. dez. 2005. (Sistema de Produção, 10). Disponível em: < http://sistemasdeproducao.cnptia. embrapa.br/>. Acesso em: 15 jul. 2013.

Uvas viníferas para processamento em regiões de clima temperado. embrapa uva e vinho. (Sistema de Produção, 4). jul. 2003. Disponível em: <http:// sistemasdeproducao.cnptia.embrapa.br/>. Acesso em: 15 jul. 2013.

EMPRESA DE PESQUISA AGROPECUÁRIA E EXTENSÃO RURAL DE SANTA CATARINA EPAGRI. Zoneamento agrícola considerando os riscos climáticos para a cultura da videira. EPAGRI - CIRAM. Florianópolis: EPAGRI, 2013. Disponível em: <http:// ciram.epagri.sc.gov.br/>. Acesso em: 15 jul. 2013.

INSTITUTO BRASILEIRO DE GEOGRAFIA E ESTATÍSTICA - IBGE. Quantidade produzida, valor da produção, área plantada e área colhida da lavoura permanente: uva: 2010. SIDRA - Sistema IBGE de Recuperação Automática. Rio de Janeiro: Instituto Brasileiro de Geografia e Estatística, 2010. Disponível em: <http://www.sidra.ibge.gov.br>. Acesso em: 15 jul. 2013.

INSTITUTO BRASILEIRO DO VINHO - IBRAVIN. Regiões produtoras. Bento Gonçalves: Instituto Brasileiro do Vinho, 2013. Disponível em: <http://www.ibravin. org.br/regioes-produtoras $>$. Acesso em: 8 jul. 2013.

INSTITUTO PARANAENSE DE DESENVOLVIMENTO ECONÔMICO E SOCIAL IPARDES. Base de Dados do Estado - BDEweb. Curitiba: Instituto Paranaense de Desenvolvimento Econômico e Social, 2013. Disponível em: <http://www.ipardes.gov. br/imp/index.php $>$. Acesso em: 8 jul. 2013.

KISHINO, A. Y.; CARAMORI, P. H. Fatores climáticos e o desenvolvimento da videira. In: KISHINO, A. Y.; CARVALHO, S. L. C.; ROBERTO, S. R. Viticultura tropical: o sistema de produção do Paraná. Londrina: IAPAR, 2007. p. 59-86.

KISHINO, A. Y.; CARVALHO, S. L. C. de; ROBERTO, S. R. Viticultura tropical: o sistema de produção do Paraná. Londrina: IAPAR, 2007. 366 p.

MINISTÉRIO DA AGRICULTURA, PECUÁRIA E ABASTECIMENTO - MAPA. Zoneamento agrícola de risco climático. Brasília: Ministério da Agricultura, Pecuária e Abastecimento, 2013. Disponível em: $<$ http:// www.agricultura.gov.br/>. Acesso em: 22 jul. 2013.

MIRANDA, E. E. (Coord.). Brasil em relevo. Campinas: Embrapa Monitoramento por Satélite, 2005. Disponível em: <http://www.relevobr.cnpm.embrapa.br>. Acesso em: 15 jul. 2013. 
PEREIRA, L. M. P.; CARAMORI, P. H.; RICCE, W. S.; SILVA, D. A. B.; CAVIGLIONE, J. H. Determinação do início e fim da estação chuvosa no estado do Paraná. Revista Geografar, Curitiba, v. 3, n. 2, p. 1-12, 2008.

POMMER, C. V. Uva: tecnologia de produção, póscolheita, mercado. Porto Alegre: Cinco Continentes, 2003. $778 \mathrm{p}$.

ROLIM, G. S.; SENTELHAS, P. C.; BARBIERI, V. Planilhas no ambiente Excel ${ }^{\text {tm }}$ para os cálculos de balanços hídricos: normal, sequencial, de cultura e de produtividade real e potencial. Revista Brasileira de Agrometeorologia, Santa Maria, v. 6, n. 1, p. 133-137, 1998.

SAMPAIO, S. C.; QUEIROZ, M. M. F.; FRIGO, E. P.; LONGO, A. J.; SUSZEK, M. Estimativa e distribuição de precipitações decendiais para o Estado do Paraná. Irriga, Botucatu, v. 12, n. 1, p. 38-53, 2007.

SOARES, J. M.; COSTA, F. F. Irrigação. In: SOARES, J. M.; LEÃO, P. C. S. (Ed.). A vitivinicultura no semiárido brasileiro. Brasília: Embrapa Informação Tecnológica, Petrolina: Embrapa Semiárido, 2009. 756 p.

TEIXEIRA, A. H.; AZEVEDO, P. V. Zoneamento agroclimático para a videira européia no Estado de Pernambuco, Brasil. Revista Brasileira de Agrometeorologia, Santa Maria, v. 4, n. 1, p. 137-141, 1996.
TEIXEIRA, A. H. C.; SOUZA, R. A.; RIBEIRO, P. H. B.; REIS, V. C. S.; SANTOS, M. G. L. Aptidão agroclimática da cultura da videira no Estado da Bahia, Brasil. Revista Brasileira de Engenharia Agrícola e Ambiental, Campina Grande, v. 6, n. 1, p. 107-111, 2002.

TESSMANN, D. J.; VIDA, J. B.; GENTA, W.; KISHINO, A. Y. Doenças e seu manejo: doenças fúngicas. In: KISHINO, A. Y.; CARVALHO, S. L. C.; ROBERTO, S. R. Viticultura tropical: o sistema de produção do Paraná. Londrina: Iapar, 2007. p. 255-287.

THORNTHWAITE, C. W.; MATHER, J. R. The water balance. Centerton, NJ: Drexel Institute of Technology - Laboratory of Climatology, 1955. v. 8, 104 p. (Publications in Climatology, n. 1).

TONIETTO, J.; FACALDE, I. Regiões vitivinícolas brasileiras: uvas para processamento. Bento Gonçalves: Embrapa Uva e Vinho, 2003. 134 p. (Frutas do Brasil, 34).

WESTPHALEN, S. L.; MALUF, J. R. T. Caracterização das áreas bioclimáticas para o cultivo de Vitis vinifera $L$. nas regiões da Serra do Noroeste e Planalto do Estado do Rio Grande do Sul. Brasília: Embrapa Comunicação para Transferência de Tecnologia; Bento Gonçalves: Embrapa Uva e Vinho, 2000. 99 p. 
